Document downloaded from:

http://hdl.handle.net/10251/104133

This paper must be cited as:

Broatch, A.; Margot, X.; Gil, A.; Galindo, E.; Soler, R. (2017). Definition of wind blowers for vehicles testing at chassis-dyno facilities using a CFD approach. Transportation Research Part D Transport and Environment. 55:99-112. doi:10.1016/j.trd.2017.06.029

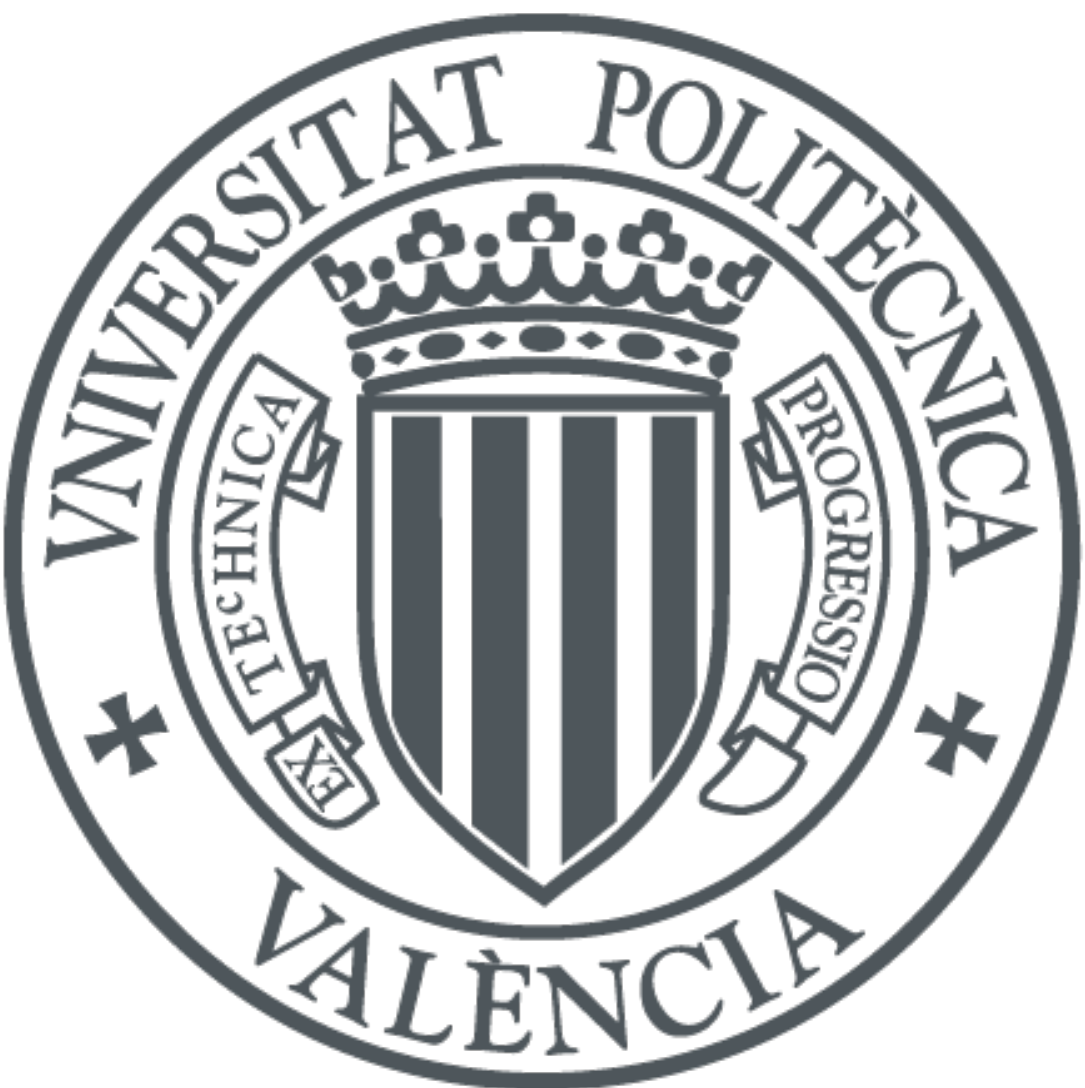

The final publication is available at

https://doi.org/10.1016/j.trd.2017.06.029

Copyright Elsevier

Additional Information 


\title{
Definition of wind blowers for vehicles testing at chassis-dyno facilities using a CFD approach
}

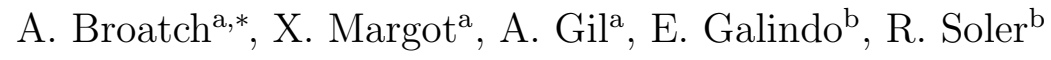 \\ ${ }^{a}$ CMT-Motores Térmicos, Universitat Politècnica de València, Aptdo. 22012, E-46071 \\ Valencia, Spain. \\ ${ }^{b}$ AVL Ibérica S.A., Oficina Valladolid, Paseo Arco de Ladrillo 68 pl.5, 47007 Valladolid, \\ Spain
}

\begin{abstract}
The need to increase measurements accuracy of fuel consumption and pollutants emissions in vehicles is forcing the market to develop chassis-dyno test cells that reproduce on-road conditions realistically.

Air-cooling is key to vehicle performance. It is therefore critical that the design of a test cell guarantees realistic cooling of all vehicle components, as important errors in fuel consumption and emissions measurements may otherwise arise. In a test-room, a blower placed in front of the vehicle supplies the cooling air. While there are some guidelines in the literature for the selection of fans required for emissions measurements at standard driving cycles, the information for designing the air supply system for specific tests in other areas is scarce.

New Real Driving Emissions (RDE) legislation will force manufacturers to perform on-road measurements of pollutants. This represents a significant challenge due to the variability of conditions coming from non-controlled
\end{abstract}

\footnotetext{
*Corresponding author. Tel.: +34 96 3877650, fax: +34963877659.

Email address: abroatch@mot.upv.es (A. Broatch)
} 
parameters. In order to optimize vehicles, different tests are performed in cells equipped with a chassis-dyno where the on-road flow field around the vehicle is reproduced as closely as possible.

This work provides some guidelines for the definition of the airflow supply system of chassis-dyno facilities for vehicle optimization tests, based on a CFD analysis of the flow characteristics around the vehicle. By comparison with the solution obtained for a vehicle in real road driving conditions, the exit section of the blower and the distance between the blower exit and the car that best reproduce realistic on-road flow conditions in a test room are determined.

Keywords: Friction vehicle testing, RDE testing, Wind blower, Chassis dyno, On-road fluid field 


\section{Introduction}

2 Pollutant emissions, fuel consumption and vehicle performance are im3 portant issues for the market of automotive vehicles (Johnson, 2009). In the 4 next decade, the development of vehicles will face new challenges. The leg5 islation will focus on both the reduction of $\mathrm{CO}_{2}$ emissions and the control of 6 in-use pollutants (Duarte et al., 2016). This horizon will force manufacturers 7 to developments based on an integral powertrain approach.

In a short-term scenario, the emission regulations will be changing from the current WLTP to a RDE testing (Tutuianu et al., 2015). These changes in the regulation (UNECE, 2014, 2015) will imply further efforts from the vehicle manufacturers to ensure that the testing conditions are as close to reality as possible.

In fact, new oncoming legislation will implement RDE testing using Portable Emissions Measurement Systems (PEMS) to measure pollutants while driving the vehicle on the roads (Frey et al., 2003; Liu et al., 2010; Wyatt et al., 2014). This poses a significant challenge for vehicle calibration, since many 
because several factors that influence emissions (e.g., road gradient, hard accelerations, use of air conditioning and traffic or weather conditions) are eliminated (Mock et al., 2013). Hence, it is important to reproduce as realistically as possible in the dyno test cell the air flow field in and around the vehicle, since it affects cooling of the different car parts and therefore also the emissions, as is justified in the following.

During the on-road operation of vehicles, the external air interacts with the vehicle. Depending on the velocity of the car, this interaction may influence more or less significantly its performance and in consequence, it must be considered as a relevant factor in vehicle design. Indeed, the air exerts a drag force on the body of the vehicle, which affects its aerodynamic performance, and is simulated later on as a drag force on the roller. In addition, it also acts as a cooling fluid for many parts of the vehicle (Jama et al., 2004, Shome et al., 2006), and this affects its mechanical efficiency. Hence, the air interaction with the vehicle has a great impact on the global efficiency of the vehicle under certain conditions.

Indeed, the air flow through the under-hood of the vehicle is crucial for engine cooling (Britcher and Stephenson, 2005) and for the intake of the air for combustion (Torregrosa et al., 2006, Khaled et al., 2011). It also contributes to cool down the exhaust line (Fernández-Yáñez et al., 2016) with the consequent impact on the performance of the after treatment devices. In vehicles with high braking-power requirements, the air flow towards the front of the vehicle is also conveyed towards the brake caliper in order to dissipate the heat generated during braking. The cabin temperature is strongly affected by the air flow around the vehicle, mainly due to the heat transfer 
across the windscreen and windows (Sanaye and Dehghandokht, 2011). The speed of the air relative to the vehicle has opposing effects on this temperature since it affects simultaneously the effectiveness of the condenser of the air conditioning system -impacting, therefore, on the system efficiency- and the vehicle conductance, which due to the convection contribution increases in proportion to the vehicle speed. In addition, the air flow around the car tires not only generates aerodynamic drag; it has also a great influence on the tire temperature, and has therefore an impact on the rolling resistance.

Chassis dynamometers are widely used in automotive industry tests to evaluate different issues related with the performance of the propulsive system. In set-ups for RDE tests, in which the pollutant emissions of the vehicle are characterized, it is crucial to reproduce the real-life operation conditions of the vehicle at speeds up to $160 \mathrm{~km} / \mathrm{h}$. While in friction tests, in which the mechanical efficiency of the complete power-train is evaluated, the target speed increases to $200 \mathrm{~km} / \mathrm{h}$. Evidently, due to the impact of the air-vehicle interaction to performance of the vehicle, both type of tests are linked by the fuel consumption and in consequence by $\mathrm{CO}_{2}$ and the other pollutants. The development of these set-ups require new testing facilities equipped with state-of-the-art components well-suited for the reproduction of the real-life vehicle operation.

Since the air interaction with all the parts of the vehicle mentioned above must be realistically reproduced, a major challenge when designing this type of bench is associated with the definition and design of the wind blower. Both the fan size and the geometrical characteristics of the nozzle (shape, length, outlet section, etc.) are critical to ensure that the behaviour of the simulated 
wind is similar to that of on-road operation. In addition, the design of the system will be also determined by the space available in the test room, which affects the relative location of the blower with respect to the vehicle.

In this work, a CFD methodology is used to determine the relevance of certain design parameters, such as nozzle exit section and distance to the car front, for a realistic simulation of on-road conditions in a facility equipped with a chassis dynamometer for RDE and friction vehicle testing.

The proposed methodology is divided in two phases. Initially, a simplified domain is considered with only the front of the car and the blower taken into account. The objective is to determine the flow field characteristics around the car in function of the distance between blower exit and the front of car, and taking into account variations of the blower exit section. In the second phase, the results are compared with the solution obtained for a calculation of the car in real road conditions. The aim of this comparison is to define the configuration that will best reproduce on-road conditions. Results show that the proposed simplified approach is suitable enough for reproducing the flow pattern around the car that allows testing vehicles at the conditions that are expected during on-road driving.

The paper is structured as follows. First, the computational domains and the CFD set-ups used for the flow simulations are presented. Then, the on-road calculation results are analysed, as they will serve as reference for the simplified domain calculations. In section 4 , the simplified wind-blower calculations performed with varying nozzle exit section and varying distance to the car front are compared with the on-road results and some conclusions are drawn from the analysis. Finally, the main conclusions are summarized 
in section 6 .

\section{Computational domain and CFD set-up}

The car manufacturers try to simulate on-road conditions by testing the car in closed rooms equipped with blowers to generate the wind and rollers for the wheels motion. However, it is important that real on-road conditions are adequately simulated in the test room, and, in particular, the blower has to be designed accordingly. In this, Computational Fluid Dynamics simulation is an ideal tool to help design all details of the test room, and it has the advantage of providing all relevant information. The modelling results of the room tests may be easily compared with real on-road simulations, and the test room design can be adjusted accordingly. In this paper, CFD is used to assess the influence of the wind blower exit section and its distance to the car front on the behavior of the flow around the car, by comparing various configurations with car on-road simulations.

This section presents the computational domains and the CFD set-up used in the flow calculations of the car studied in real on-road conditions and in the test room with different wind blower configurations. The on-road conditions serve to validate the design of the blower.

The vehicle studied is based on a simplified model of a generic car bodywork that includes the most significant details of the car shape required for the present simulation. Figure 1 shows the geometry of the car considered.

Two types of calculations have been carried out:

1. Air flow around a car on the road. 
2. Air flow around a car placed in a test-cell equipped with a fan blowing air through a duct to simulate the on-road front wind.

\subsection{Computational domain for the on-road scenario}

The simulation of a car in real road conditions requires the use of an extended domain to ensure that the flow is undisturbed far upstream and far downstream of the car, as would be the case in real conditions. Since it is necessary to have a fairly fine mesh around the car body to solve adequately the boundary layer, but also in the wake area, mesh quality criteria impose a very large number of cells.

In Figure 2 the mesh generated to simulate the flow around the car in real road conditions is presented: its size defined in car lengths is 21 downstream, 10 upstream and 4 in height. A cut-cell Cartesian approach (Ingram et al.,2003) has been used in this case, due to the benefits this type of mesh generation offers. Indeed, it allows to accurately body-fit the complex geometry of the car, while maintaining a good mesh quality with adequate fine resolution at the walls In this case, the cell size ranges from a minimum of $0.004 \mathrm{~m}$ to a maximum of $0.500 \mathrm{~m}$ in the computational domain representing the on-road calculation, with a total of $3.0 \mathrm{E}+06$ cells.

A velocity inlet boundary condition of $55,55 \mathrm{~m} / \mathrm{s}(200 \mathrm{~km} / \mathrm{h})$ is imposed upstream of the car in order to reproduce the relative axial wind, while pressure atmospheric conditions are set at the downstream, upper and outer side surrounding boundaries. In order to reduce the number of cells of the mesh, only one half of the car domain is calculated, considering the symmetry plane along the car length. Naturally, in this case the wind can have no yaw angle, but the flow in a test room is generally considered in the axial direction 
of the car only. Finally, the road (wall boundary condition) is simulated as a slip-wall boundary with a relative velocity equal to the car velocity in order to reproduce the relative motion between the road and the vehicle, which is important to take into account road boundary layer interference with the wheels.

\subsection{Computational domain for the test cell equipped with a wind blower}

The purpose of this test cell calculation is to reproduce the experimental conditions in which the car is tested. Experimentally, the car is placed in a test room fully equipped with a fan blowing air through a duct that simulates the front flow. However, the main focus of this paper is to study the influence of the upstream flow on the front of the car, mainly for cooling purposes, and the capability to reproduce the frontal air flow arriving over the car in a real on-road test. Hence, the problem in CFD has been simplified by reducing the computational domain to the blower and the upstream part of the test room including the front part of the car (see Figure 3).

The dimensions of the sub-domain corresponding to the test cell are $8 \mathrm{~m}$ width $\times 5$ m length $\times 3 \mathrm{~m}$ height. As for the on-road simulations, the meshing procedure used was the cut-cell Cartesian approach, with the different cell sizes ranging from a minimum of $0.004 \mathrm{~m}$ to a maximum of $0.125 \mathrm{~m}$, and a total of $1.5 \mathrm{E}+06$ cells. In order to ensure the accuracy of the selected special discretization, a mesh independence study has been carried out for one of the wind blower test cases taken into account in this study (H1100-D300, see Table 1). Minimum cell size has been decreased to $0.002 \mathrm{~m}$ and $0.001 \mathrm{~m}$, and number of cells of the refined mesh are $8.5 \mathrm{E}+06$ and $14.0 \mathrm{E}+06$ respectively. Figure 4 shows the pressure profile along a line located in the symmetry 
plane of the car surface (as shows the sketch in the figure). It is clear that no significant differences of pressure field can be found around the car for different meshes, therefore the coarser mesh has been used for the study in order to optimize computational resources.

At the inlet boundary represented by the cylindrical output surface of the blower rotor, a total pressure boundary condition is imposed, adjusted in order to provide an average velocity of $200 \mathrm{~km} / \mathrm{h}$ at the outlet of the nozzle for every nozzle configuration. A symmetry plane has also been considered for the whole domain in order to reduce the number of cells. Finally, the downstream and outer surrounding boundaries have been defined as pressure outlet at atmospheric conditions.

Different blower configurations have been modeled in order to perform parametric studies, such as the influence of the blower outlet surface and the distance of this outlet to the car front.

\subsection{CFD set-up}

For this study, the flow was considered steady, incompressible and turbulent. The finite volume commercial program ANSYS-Fluent 15 based on the pressure based approach was used for the CFD simulations. A segregated solution algorithm and an implicit formulation with a first-order spatial discretization scheme were chosen to solve numerically the algebraic Navier-Stokes equations. The coupling between the momentum and continuity equations was achieved with the SIMPLE algorithm. The RANS SpalartAllmaras (S-A) turbulence model (Spalart et al., 1992) was used for closure. S-A model is known to provide accurate results on external flows with mild separation (Spalart, 2000) with reduced computational cost. Similar stud- 
ies on vehicular aerodynamics have been successfully performed with RANS calculations for drag analysis and aeroacoustics (Nebenfuhr, 2010; Chauchan et al., 2012) for both simplified or real bodyworks. Finally, convergence to steady-state and stability were monitored by checking the equations residuals, and by controlling the evolution towards steady state of the significant variables (pressure, velocity, turbulence) at different monitor locations of the computational domain.

\section{Results of on-road calculations}

\subsection{Analysis of the flow around the car}

As the wind blower simulation tests should be representative of the onroad flow around the car, the flow pattern obtained from the on-road calculation is the reference to which other calculations will be compared. Hence, it is interesting to look at the important features of the flow around the car in on-road conditions. Figure 5 represents the velocity field around the car.

As may be observed, there are clearly zones where the flow has very low velocity. Indeed, as expected, there is a stagnation zone of near zero velocity at the front of the car (see zoom of car front).

From the stagnation point located at about half height of the car front, the flow separates, one part flowing over the bonnet, the rest underneath the car. Looking more closely at Figure 5, there are two additional zones where the flow has almost zero velocity. First, under the car, where the flow coming from the front turns to reach underneath; as it cannot adapt fast enough to the sharp turn around the car geometry, the streamlines are projected towards the floor, leaving a small recirculation zone just underneath the car 
bottom. The other zone is the stagnation area due to the direction change between the bonnet and the windshield. After the initial acceleration from the front over the bonnet, the flow encounters the windshield and a very small recirculation area is generated just at the bottom of it, before accelerating again. Since the windshield connects smoothly with the roof, there is no flow separation in that area.

\subsection{Car surface pressure analysis}

The previous analysis gives an indication of the airflow around the vehicle. However, when it comes to vehicle tests, it is most important to reproduce adequately the pressure distribution on the surface itself, as this is a determinant factor for the car performance.

Figure 6 shows the pressure distribution on the upper surface and at the bottom of the vehicle. The pressure at the front of the car is close to stagnation values, as expected, since the upstream flow hits the car front and is stopped in the middle (see Figure 6).

As the air accelerates over the hood, pressure decreases gradually. It then increases at the jointure between bonnet and windshield, where naturally the front flow is again stopped, before accelerating again to pass over the roof.

The bottom surface shows how the flow slightly decelerates from front to back, with high pressure seen at the front of each wheel, as expected.

\section{Results of wind blower test cell calculations}

The main objective here is to study the ability of the wind blower tests to reproduce adequately the on-road cooling conditions for different zones of the car (see Figure 7). For this, as indicated in section 2, a parametric study has 
been performed, by varying on the one hand the height of the wind blower exit section (see Figure 8) and on the other hand, the distance between the car front and the wind blower exit. In order to simplify the study, the width of the blower exit and its height from the floor have been fixed. With the aim to cover a wide range of vehicles width, the width of the blower exit in this study is $1,4 \mathrm{~m}$. In contrast to the $200 \mathrm{~mm}$ indicated by Regulation 83 UNECE, the height of the blower exit considered here was $20 \mathrm{~mm}$ in order to best reproduce the airflow underneath the vehicle. Table 1 summarizes the cases presented.

The results of these calculations are presented in terms of car surface pressure contours in Figure 9, Figure 10 and Figure 11.

Figure 9 shows clearly that both height of the blower exit and distance to the car front influence significantly the pressure distribution over the car front surface. In particular, in comparison with the on-road calculation presented in Figure 6, the pressure at the front of the car and in front of the wheels is over-estimated by about double in the cases when the car front is at the smallest distance $(300 \mathrm{~mm})$, more so for the smallest section height of the blower exit $(700 \mathrm{~mm})$. This means that the cooling conditions for the under-hood (zone 1 of Figure 7) and brakes (zone 2 of Figure 7) of the car are not adequately represented if the car is too close to the blower exit. However, all four configurations yield very similar results for the pressure on the hood and windshield, and similar to the on-road conditions (zone 4 of Figure 7). Looking at the front of the car, the best representation of the on-road conditions is therefore given by the case H1100-D1000, while H700-D1000 also gives pretty good results. 
Figure 10 shows the pressure contours on the car side. It is worth noting that the pressure distribution is fairly uniform along the side of the car according to the on-road calculation (see Figure 6). All test-cell configurations yield indeed a quasi-uniform distribution also, especially the two cases corresponding to the blower exit of height $700 \mathrm{~mm}$. However, none of the cases reproduces exactly the on-road conditions, especially towards the front and in the windshield area. This is probably not very important, considering the uniformity of the pressure and the fact that only the side entrance cooling would be affected (zone 4 of Figure 7). From the point of view of the air flow on tires (zone 5 of Figure 7), it is the case H1100-D1000 which best reproduces on-road conditions, even though there are no great differences with the other configurations.

Figure 11 presents the pressure distribution underneath the car. Although there are some differences in the pressure distribution of the different wind blower configurations, they are of the order of $1000 \mathrm{~Pa}$ and therefore not very significant. Clearly, none of the configurations show the higher uniformity of the on-road bottom pressure distribution (Figure 6). This may be explained by the fact that in the wind blower cases, the floor boundary conditions do not take into account the wheels motion. Indeed, for the on-road simulation the road is moving relative to the vehicle in the same direction as the air, whereas in the blower simulation the road has zero velocity. Basically, in order to obtain a better prediction for zone 3 in Figure 7 , the relative movement of the wheels on the floor should be considered also in the CFD wind blower calculations. 


\section{Quantitative comparison between wind blower and on-road re- sults}

Figure 12 and Figure 13 present the quantitative comparison of each wind blower calculation with respect to the on-road calculation, in terms of pressure difference, i.e. $\Delta p=p_{\text {blower }}-p_{\text {on-road }}$.

As seen by the scale, these images confirm the observations made in section 4. Indeed, the highest difference in pressure with respect to onroad calculations corresponds to the cases when the car front is at $300 \mathrm{~mm}$ of the nozzle exit. Moreover, the maximum difference, which is of the order of $2500 \mathrm{~Pa}$, appears in front of the car and in front of the wheels for the case H700-D300. Clearly, the two D300 cases over-predict the frontal pressure and represent therefore a poor prediction of the on-road cooling for zones 1 (under-hood), 2 (brakes) and 5 (tires). For the hood and windshield areas, the prediction is much better in all cases. For the cases H1100-D1000 and H700-D1000 the pressure difference with respect to the on-road calculation is practically zero almost everywhere over the frontal surface, with a maximum difference of about $500 \mathrm{~Pa}$ on the hood and windshield.

According to Figure 13, all wind-blower configurations yield very similar results, with the worst prediction given again by case H700-D300, especially ahead of the wheels. In all cases, the maximum difference (about $2500 \mathrm{~Pa}$ ) is in the area of the windshield lateral. At wheel level (zone 5), the pressure difference with respect to the on-road result is of the order $1500 \mathrm{~Pa}$. It is not clear which configuration yields the best results in this case.

Figure 14 summarizes the results presented above in a quantitative mode, by showing the pressure difference between each of the cases described above 
and the on-road case along the symmetry line and a horizontal side line along the bodywork. The zero axis corresponds to a zero pressure difference with the on-road results. Along the symmetry line (Figure 14a), the peaks correspond to the changes in flow direction: front to hood, hood to windshield, and windshield to roof. The graphic confirms that the worst test cell configurations correspond to the cases when the car is closest to the blower exit $(\mathrm{D}=300 \mathrm{~mm})$. Indeed, especially at the front surface of the car, these test cell calculations predict an over-pressure of up to $2500 \mathrm{~Pa}$ with respect to on-road conditions, and up to $1000 \mathrm{~Pa}$ in the area of the windshield. Curiously, the trend is inverted when looking at the roof pressure. Both cases H700-D1000 and H1100-D1000 yield a very similar pressure distribution to that of the on-road calculation, especially along the hood and windshield, so that the airflow for zones 4 (Figure 7 ) is well represented if the car is at a distance of $1000 \mathrm{~mm}$ from the blower exit. At the car front, the maximum pressure difference for these cases is about $200 \mathrm{~Pa}$, which means that zones 1 and 2 (Figure 7) are also well represented.

When looking at the pressure difference along the side line (Figure 14b), clearly, the best representation for on-road flow conditions along the lateral of the car is obtained with the cases $\mathrm{H}=1100 \mathrm{~mm}$, i.e. for the largest blower exit section. Ahead of the wheel, the maximum pressure difference is about $400 \mathrm{~Pa}$, in the wheel area, $500 \mathrm{~Pa}$, and even less behind the wheel (about $200 \mathrm{~Pa})$. When the blower exit section is smaller $(\mathrm{H}=700 \mathrm{~mm})$, results are less accurate, with about $700 \mathrm{~Pa}$ pressure difference ahead of the wheel. This means that the wind blower exit has to be high enough to represent adequately the airflow around the car in zones 2 (brakes cooling) and 5 
(tires) of Figure 7.

The important issue is to conclude which is the configuration which best reproduces the on-road conditions. To this purpose, the velocity fields around the car obtained with the four wind blower test cell configurations cases are compared to that of the on-road simulation (Figure 15).

The case of the largest exit section and largest distance (case H1100D1000) is similar in the important features. It reproduces properly the stagnation area at the front of the car, as well as the zone of moderately high velocities over the hood. It also shows a similar deceleration in the area of the hood-windshield junction, and a new acceleration to get over the car roof. Since the flow disturbance extends further out in this case than in the other ones, it is more similar to on-road far-field conditions.

Figure 16 is a view of a plane $200 \mathrm{~mm}$ in front of the car in terms of velocity difference between wind blower and on-road calculations. It shows that the distance between car front and blower exit is a more influential parameter than the exit area of the nozzle. Indeed, with a distance of 300 $\mathrm{mm}$ the velocity is clearly over-predicted by in between $18 \mathrm{~m} / \mathrm{s}$ at the center and $50-60 \mathrm{~m} / \mathrm{s}$ on the sides, independently of the blower exit height. At 1000 $\mathrm{mm}$ distance however, the zones where the flow velocity is over-predicted are smaller and limited to side areas where the flow does not impinge directly on the car for both exit heights.

On the other hand, comparing the cases with different blower exit heights at the same blower exit-car distance, it is clear that the zones of velocity over-prediction are similar, though slightly more extended for the smallest height (H700 mm). It confirms that the on-road flow ahead of the car is best 
represented by case H1100-D1000, as already observed above.

\section{Conclusions}

A CFD study has been performed to help design the wind blower configuration of a test cell used to simulate the air flow around a vehicle in on-road conditions. For this, four different wind blower configurations have been studied, whereby the height of the blower duct exit has been varied, as well as the distance between car front and blower exit. The resulting flow patterns of all four calculations have then been compared to the calculated flow field around the vehicle in on-road conditions.

The analysis of the results has been focused on determining how well any of the wind blower configurations might represent the real on-road conditions from the point of view of the cooling of the different parts of the car. The main conclusions are summarized in Table 2.

Most of the blower configuration results show higher or equal air speed/pressure over the vehicle compared to the on road scenario. Since the cooling of the car parts is related to the velocity/pressure distribution, this means that the there is an over-prediction of the cooling conditions with the blower configuration. As has been noted above in this document, the effective cooling over specific parts of the vehicle can affect pollutant emissions. Hence, it is important to achieve the least difference in air speed/pressure (and thus cooling) between blower and on-road configurations.

The results in Table 2 allow concluding that the outlet area of the blower and the distance between the blower and the car both have a significant influence on the flow around the vehicle. However, the results show that the 
distance at which the outlet of the nozzle is located has a greater impact on the flow around the vehicle than the section of the nozzle. Indeed, the blower with a nozzle of $1400 \times 1100 \mathrm{~mm}$ located at the largest distance from the vehicle $(1000 \mathrm{~mm})$ yields the most accurate representation of the flow around the whole vehicle. However, reducing the height of the blower section means that the simulation is slightly less accurate, but still within acceptable levels.

Given the results of the present work, in order to reproduce RDE tests, the ideal dimensions for blowers of chassis dynamometer facilities should be $1400 \times 1100 \mathrm{~mm}$, provided it is located at a sufficient distance from the car. If higher air speeds are needed, the nozzle section could be reduced to 1400x700 mm in order not to increase the flow rate too much and still obtain reasonable results.

\section{References}

Britcher, C., Stephenson, P., 2005. Aerodynamic calibration of an automotive climatic wind tunnel. In: 41st AIAA/ASME/SAE/ASEE Joint Propulsion Conference \& Exhibit, 10-13 July, Tucson, Arizona.

Chauhan Rajsinh B., Thundil Karuppa Raj R., 2012. Numerical Investigation of External Flow around the Ahmed Reference Body Using Computational Fluid Dynamics. Res. J. Recent Sci. 1(9), 1-5.

Duarte, G.O., Gonçalves, G.A., Farias, T.L., 2016. Analysis of fuel consumption and pollutant emissions of regulated and alternative driving cycles based on real-world measurements. Transp. Res. Part D-Trans. Environ. 
44, 43-54.

Frey, H.C., Unal, A., Rouphail, N.M., Colyar, J.D., 2003. On-road measurement of vehicle tailpipe emissions using a portable instrument. J. Air Waste Manag.Assoc. 53 (8), 9921002.

Gis, W., Zoltowski A., Taubert, S., 2011. The impact of engine cooling fan configuration on the emission of pollutants by vehicle exhaust systems in chassis dynamometer tests. Journal of KONES Powertrain and Transport, Vol. 18, No. 3.

Ingram, D.M., Causon, D.M., Mingham, C.G., 2003. Development in Cartesian cut-cell methods. Mathematics and Computers in Simulation 61, 561572 .

Jama, H., Watkins, S., Dixon, C., Ng, E., 2004. Airflow distribution through the radiator of a typical Australian passenger car. 15th Australasian Fluid Mechanics Conference, Sydney, 13-17 December 2004.

Johnson, T.V., 2009. Review of diesel emissions and control. International Journal of Engine Research 10(5), 275-285.

Fernández-Yáñez, P., Armas, O., Martínez-Martínez, S., 2016. Impact of relative position vehicle-wind blower in a roller test bench under climatic chamber. Applied Thermal Engineering 106, 266-274. 
Khaled, M., Harambat, F., Peerhossaini, H., 2011. Towards the control of car underhood thermal conditions. Applied Thermal Engineering 31, 902-910.

Liu, H.A., Barth, M., Scora, G., Davis, N., Lents, J., 2010. Using portable emission measurement systems for transportation emissions studies comparison with laboratory methods. Transp. Res. Rec. 2158, 5460.

Mock, P., German, J., Bandivadekar, A., Riemersma, I., Ligterink, N., Lambrecht, U., 2013. From Laboratory to Road. A Comparison of Official and 'Real-world' Fuel Consumption and CO2 Values for Cars in Europe and the United States: ICCT White Paper.

Nebenfuhr B., 2010. 'A tool for predicting automotive relevant flow fields'. PhD thesis, Chalmers University of Technology, Göteborg, Sweden.

Pathak, S.K.,Sood, V., Singha Y., Channiwala, S.A., 2016. Real world vehicle emissions: Their correlation with driving parameters. Transp. Res. Part D-Trans. Environ. 44, 157-176.

Sanaye, S., Dehghandokht, M., 2011. Thermal modeling for predication of automobile cabin air temperature. International Journal of Automotive Engineering 1(3), 152-164.

Shome, B., Kumar, V., Kumar, S.V.R., Arora, G., 2006. CFD prediction to 
optimize front end cooling module of a passenger vehicle. International Refrigeration and Air conditioning Conference, Indiana, 15-20 July 2006, Paper 845 .

Spalart, P.R., Allmaras, S.R, 1992. A One-Equation Turbulence Model for Aerodynamic Flows. 30th Aerospace Sciences Meeting and Exhibit, Reno NV, 6-9 January 1992.

Spalart P.R., 2000. Strategies for turbulence modelling and simulations. International Journal of Heat and Fluid Flow 21, 252-263.

Torregrosa A.J., Olmeda P., Martín J., Degraeuwe B., 2006. Experiments on the influence of inlet charge and coolant temperature on performance and emissions of a DI Diesel engine. Experimental Thermal and Fluid Science 30, 633-641.

Tutuianu, M., Bonnel, P., Ciuffo, B., Haniu, T., Ichikawa, N., Marotta, A., Pavlovic, J., Steven, H., 2015. Development of the World-wide harmonized Light duty Test Cycle (WLTC) and a possible pathway for its introduction in the European legislation. Transp. Res. Part D-Trans. Environ. 40, 61-75.

UN Economic Commission for Europe (UNECE), 2014. Global technical regulation on Worldwide harmonized Light vehicles Test Procedure. Addendum 15: Global technical regulation No. 15. 
494 UN Economic Commission for Europe (UNECE), 2015. Uniform provisions 495 concerning the approval of vehicles with regard to the emission of pollutants 496 according to engine fuel requirements. Addendum 82: Regulation No. 83, 497 Revision 5, Geneva.

498

${ }_{499}$ Wyatt, D.W., Li, H., Tate, J.E., 2014. The impact of road grade on carbon 500 dioxide $\left(\mathrm{CO}_{2}\right)$ emission of a passenger vehicle in real-world driving. Transp. 501 Res. Part D-Trans. Environ. 32, 160170. 


\section{Figures captions}

Fig. 1 CAD car model bodywork.

Fig. 2 Mesh around the vehicle for on-road calculations.

Fig. 3 Mesh around the vehicle and blower for test cell calculations.

Fig. 4 Pressure along front/top symmetry line. Mesh independence study.

Fig. 5 Velocity field around the vehicle in the symmetry plane (bottom), and zoom around the front on the road scenario.

Fig. 6 On-road calculations results: pressure distribution over car. (a) Front View, (b) Side View, (c) Bottom View.

Fig. 7 Identification of the zones of interest in the dynamo test cells.

Fig. 8 Dimensions of the blower outlet sections.

Fig. 9 Wind blower test cell results: Front view of car surface pressure distribution.

Fig. 10 Wind blower test cell results: Side view of car surface pressure distribution.

Fig. 11 Wind blower test cell results: Bottom view of car surface pressure distribution.

Fig. 12 Pressure difference on car front bodywork between wind blower (test cell) and on-road result.

Fig. 13 Pressure difference on car side bodywork between wind blower (test 
522 cell) and on-road result.

${ }_{523}$ Fig. $14 \Delta p=p_{\text {blower }}-p_{\text {on-road }}$ calculated values for the studied wind blower 524 configurations. Front/Top Symmetry Line (top) and Side Line at $0.50 \mathrm{~m}$ 525 height(bottom).

${ }_{526}$ Fig. 15 Velocity field contours on the vehicle in the symmetry plane.

${ }_{527}$ Fig. 16 Velocity difference (wind blower-on-road) on plane located at $200 \mathrm{~mm}$ 528 in front of the car.

529

530 
Table 1: Cases considered in the study.

\begin{tabular}{ccc}
\hline Case & $\begin{array}{c}\text { Blower exit height } \\
(\mathrm{mm})\end{array}$ & $\begin{array}{c}\text { Distance car front-blower exit section } \\
(\mathrm{mm})\end{array}$ \\
\hline H1100-D300 & 1100 & 300 \\
H1100-D1000 & 1100 & 1000 \\
H700-D300 & 700 & 300 \\
H700-D1000 & 700 & 1000 \\
\hline
\end{tabular}


Table 2: Summary of comparison between wind blower calculations and on-road case.

Zone of the car (see Figure 7)

H1100-D300 H1100-D1000 H700-D300 H700-D1000

1. Under hood air ducting

Good Very good Over speed Good

Radiators

Good

Very good

Lightly

overcooled

Good

Engine cooling

Good

Very good

Lightly

Air intake

Good

Very good

Over speed

overcooled

Good

Tires and brakes

Overcooled

Good

Overcooled

Good

2. Brakes cooling

Overcooled

Good

Overcooled

Good

3. Underneath vehicle flow

$$
\text { Lightly }
$$

overcooled

Good

Lightly

Lightly

4. Air flow around the vehicle overcooled

Good overcooled

Good Lightly

Overcooled

Good Lightly overcooled

5. Air flow on tires

Overcooled overcooled

Lightly overcooled 


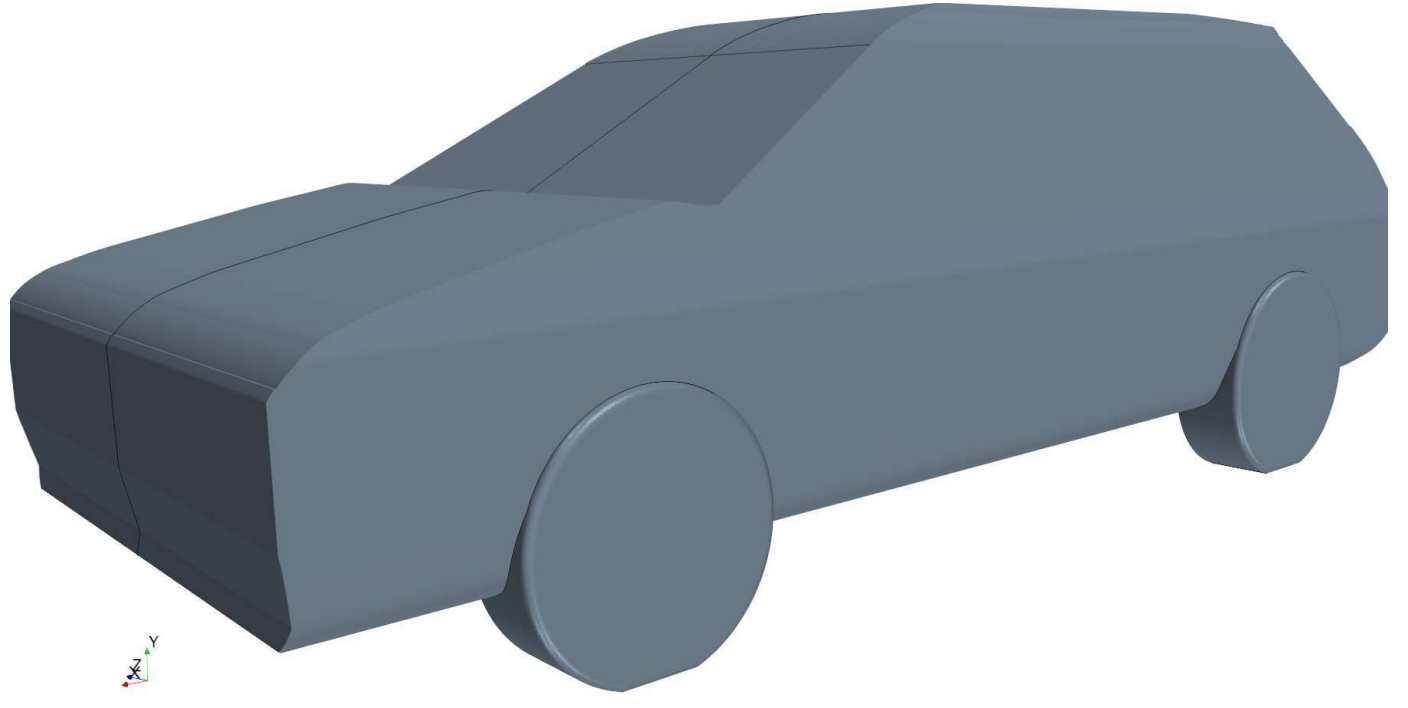

Figure 1: CAD car model bodywork.

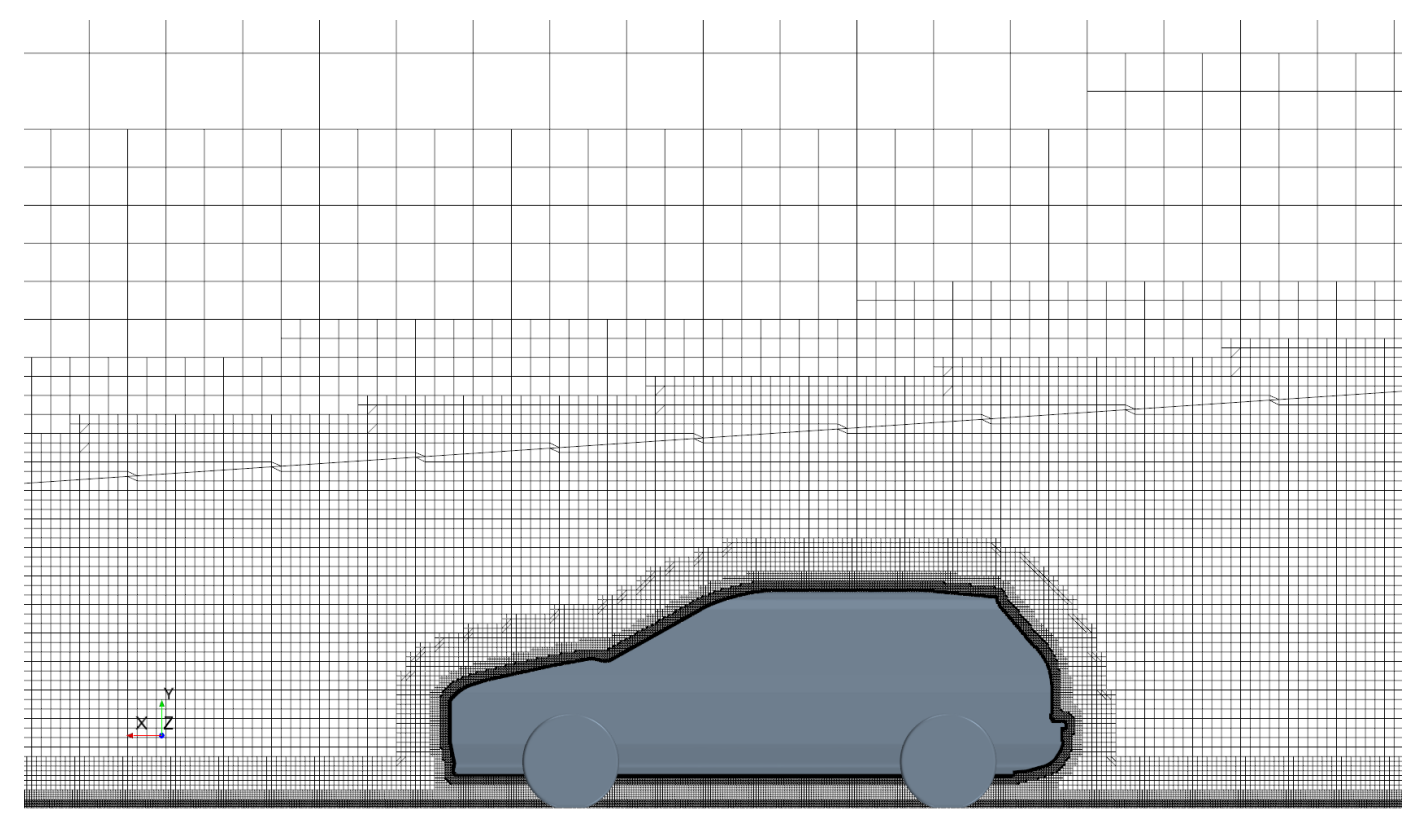

Figure 2: Mesh around the vehicle for on-road calculations. 


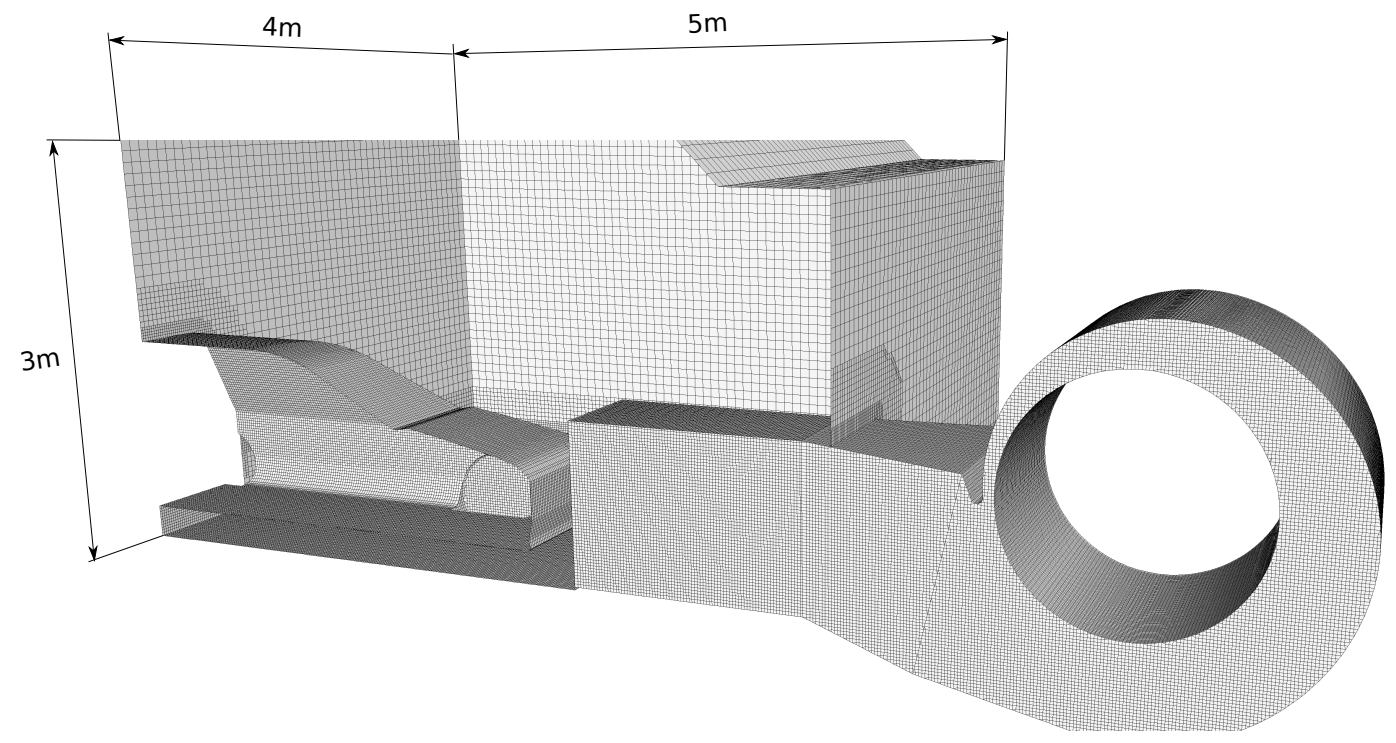

Figure 3: Mesh around the vehicle and blower for test cell calculations.

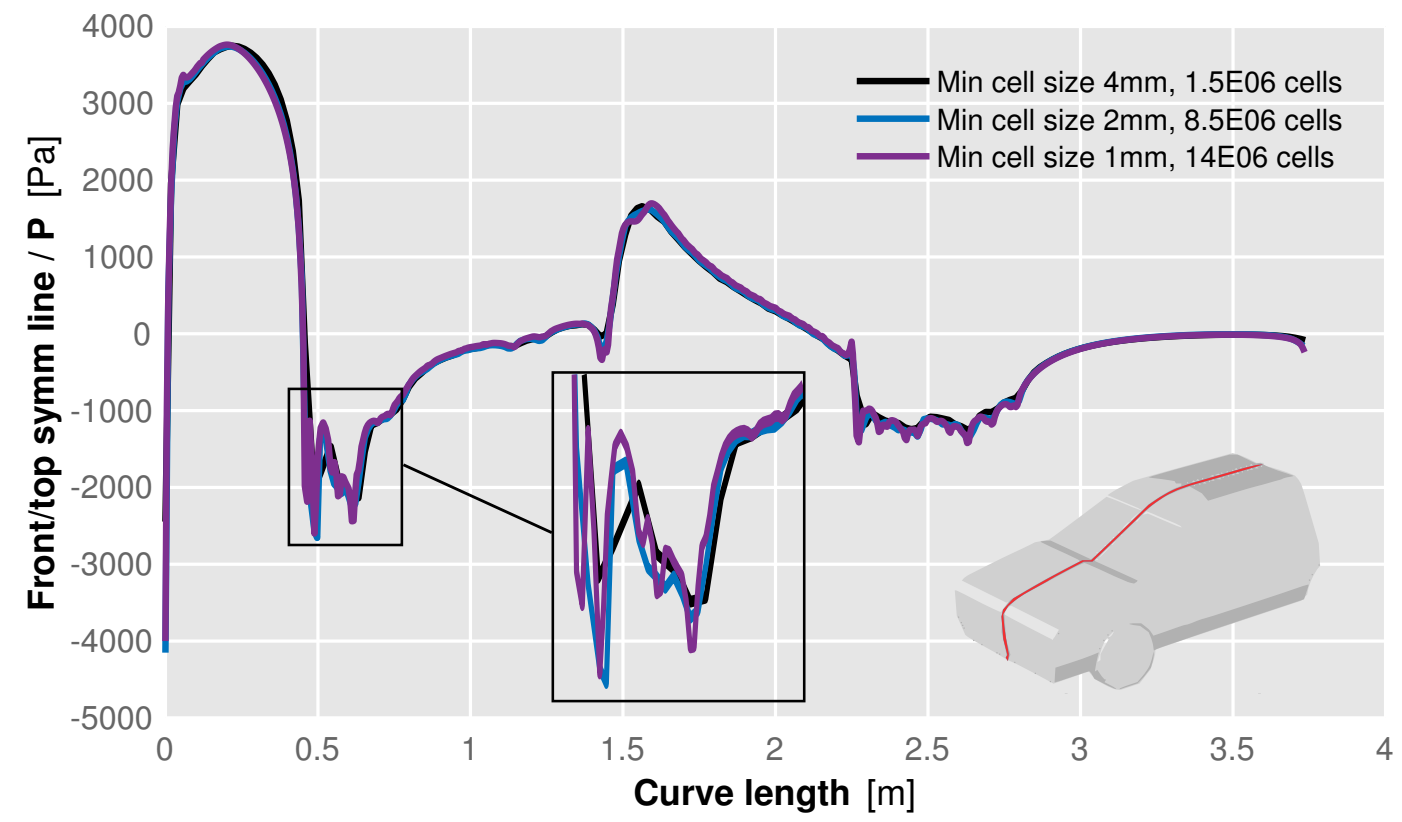

Figure 4: Pressure along front/top symmetry line. Mesh independence study. 

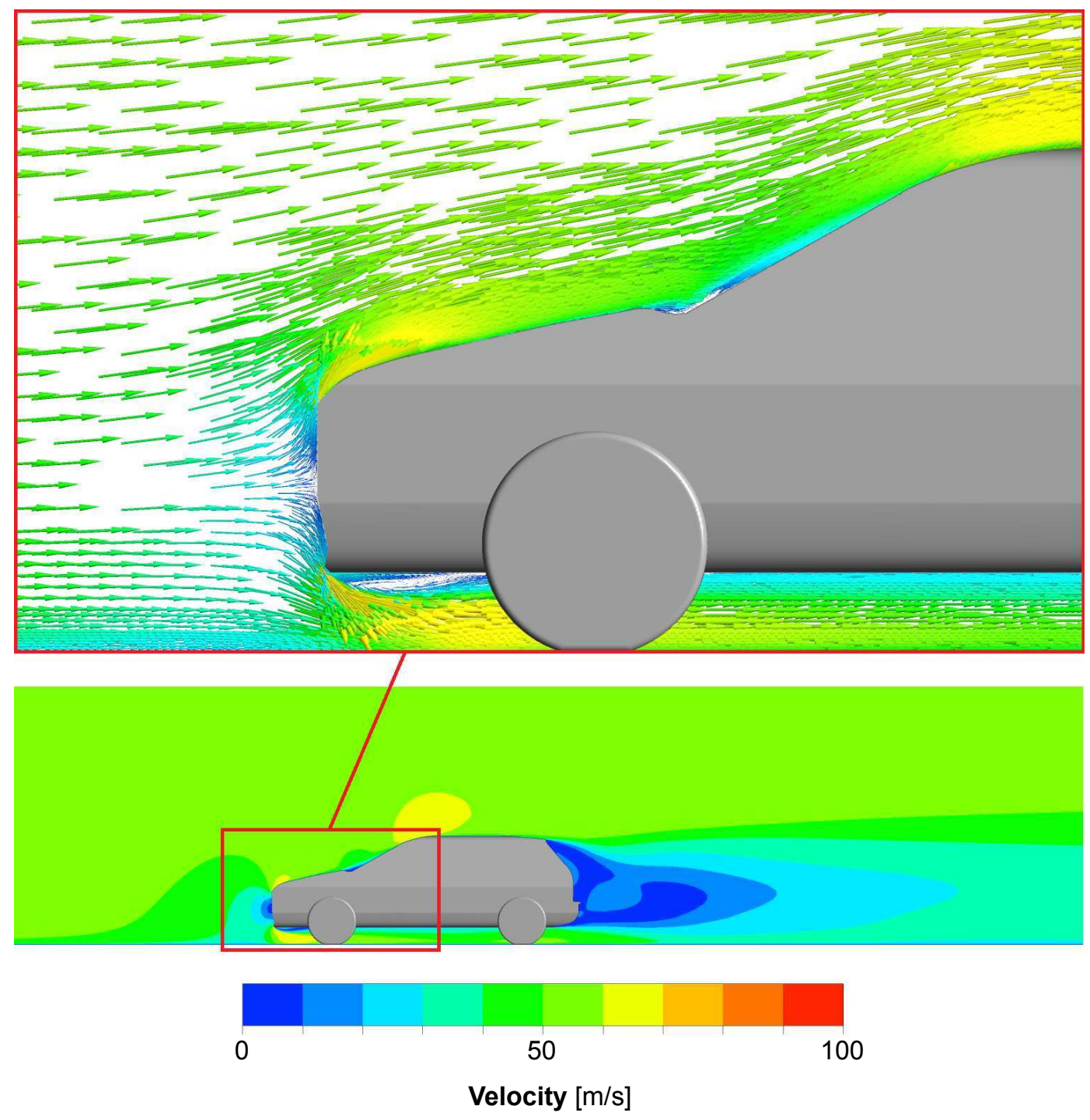

Figure 5: Velocity field around the vehicle in the symmetry plane (bottom), and zoom around the front on the road scenario. 


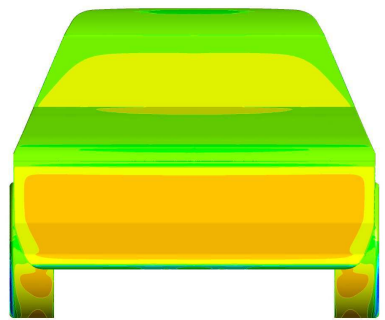

(a) Front view

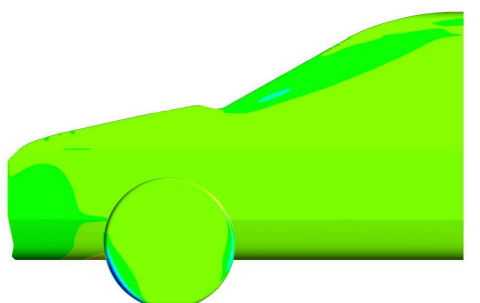

(b) Side view

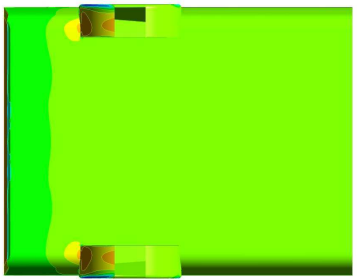

(c) Bottom view

Pressure $[\mathrm{kPa}]$

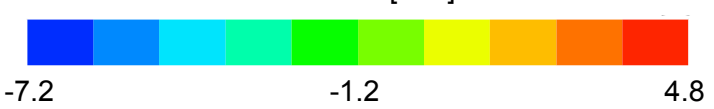

Figure 6: On-road calculations results: pressure distribution over car. (a) Front View, (b) Side View, (c) Bottom View.

Zone 4

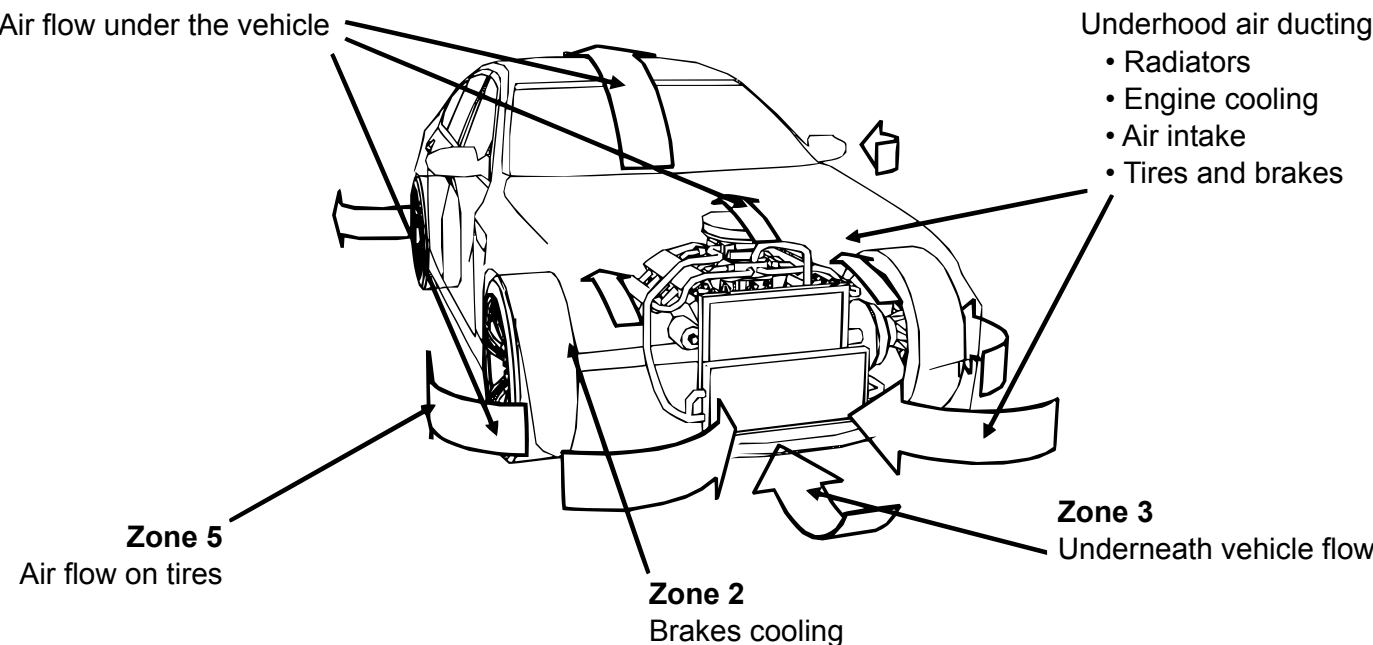

Figure 7: Identification of the zones of interest in the dynamo test cells. 

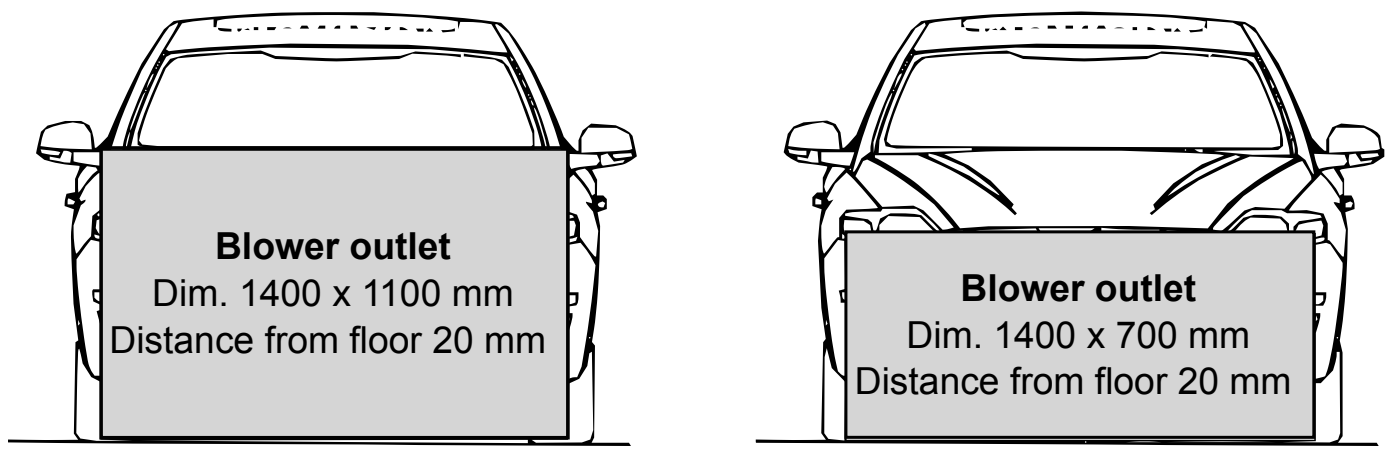

Figure 8: Dimensions of the blower outlet sections. 


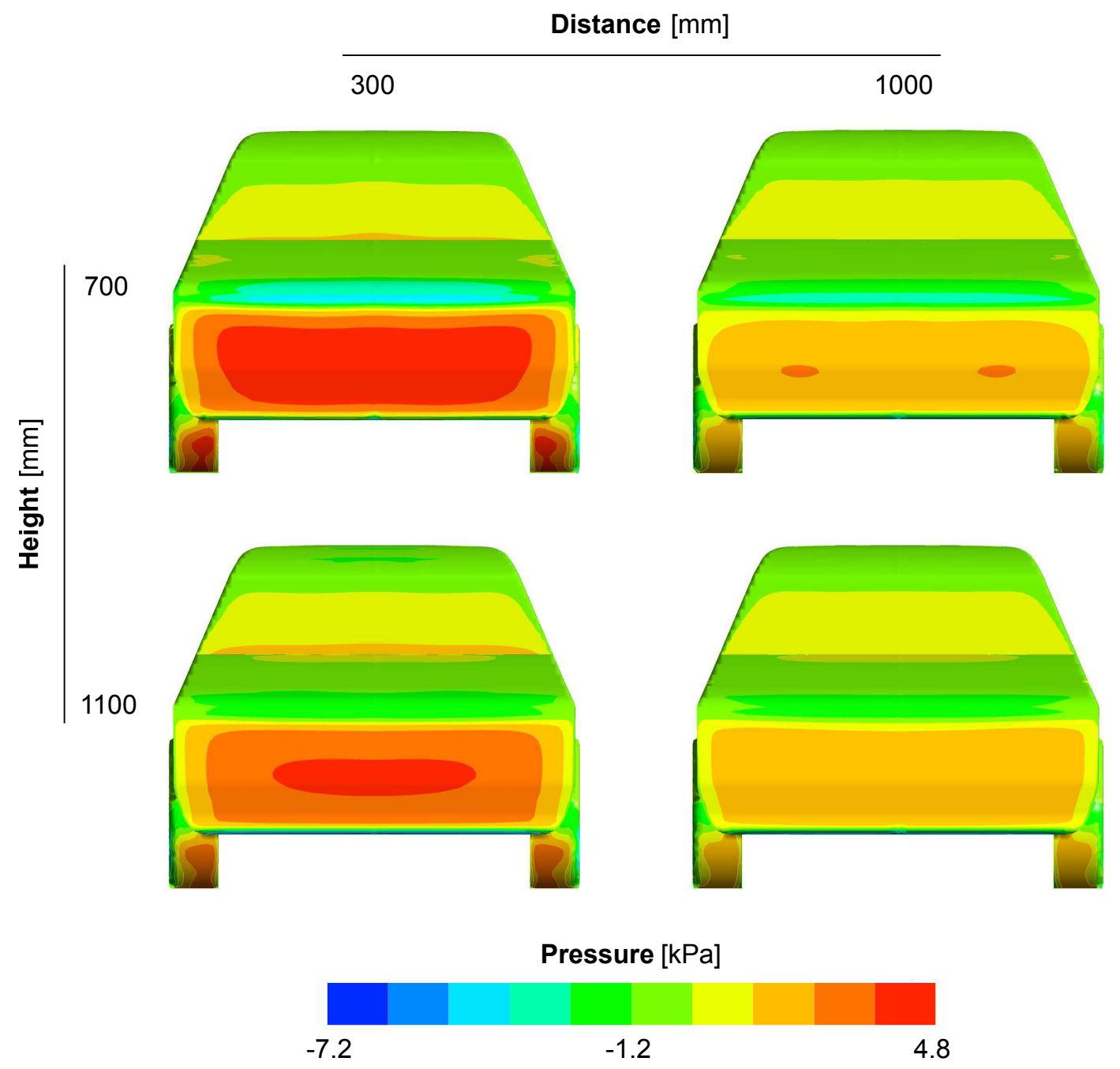

Figure 9: Wind blower test cell results: Front view of car surface pressure distribution. 


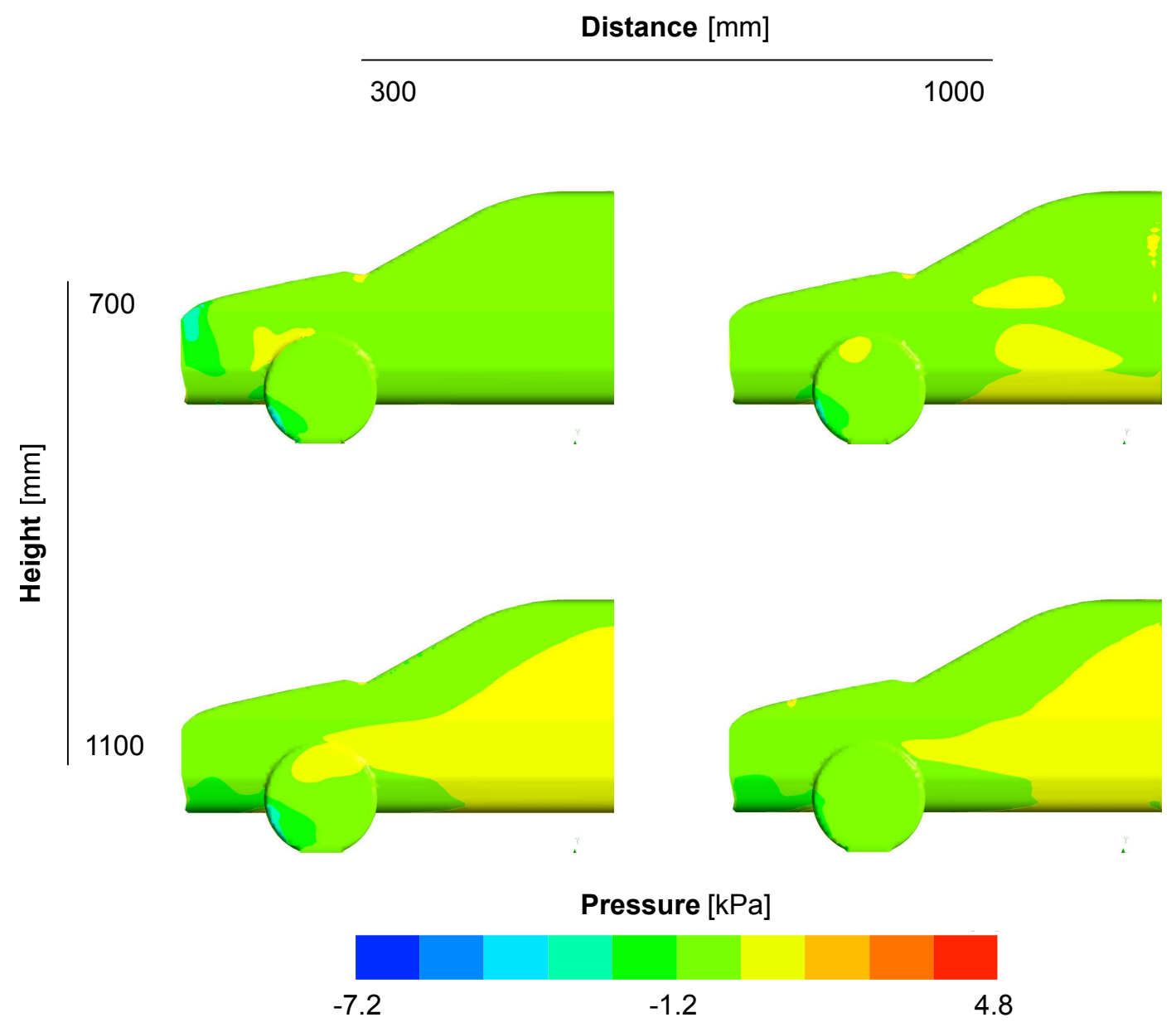

Figure 10: Wind blower test cell results: Side view of car surface pressure distribution. 


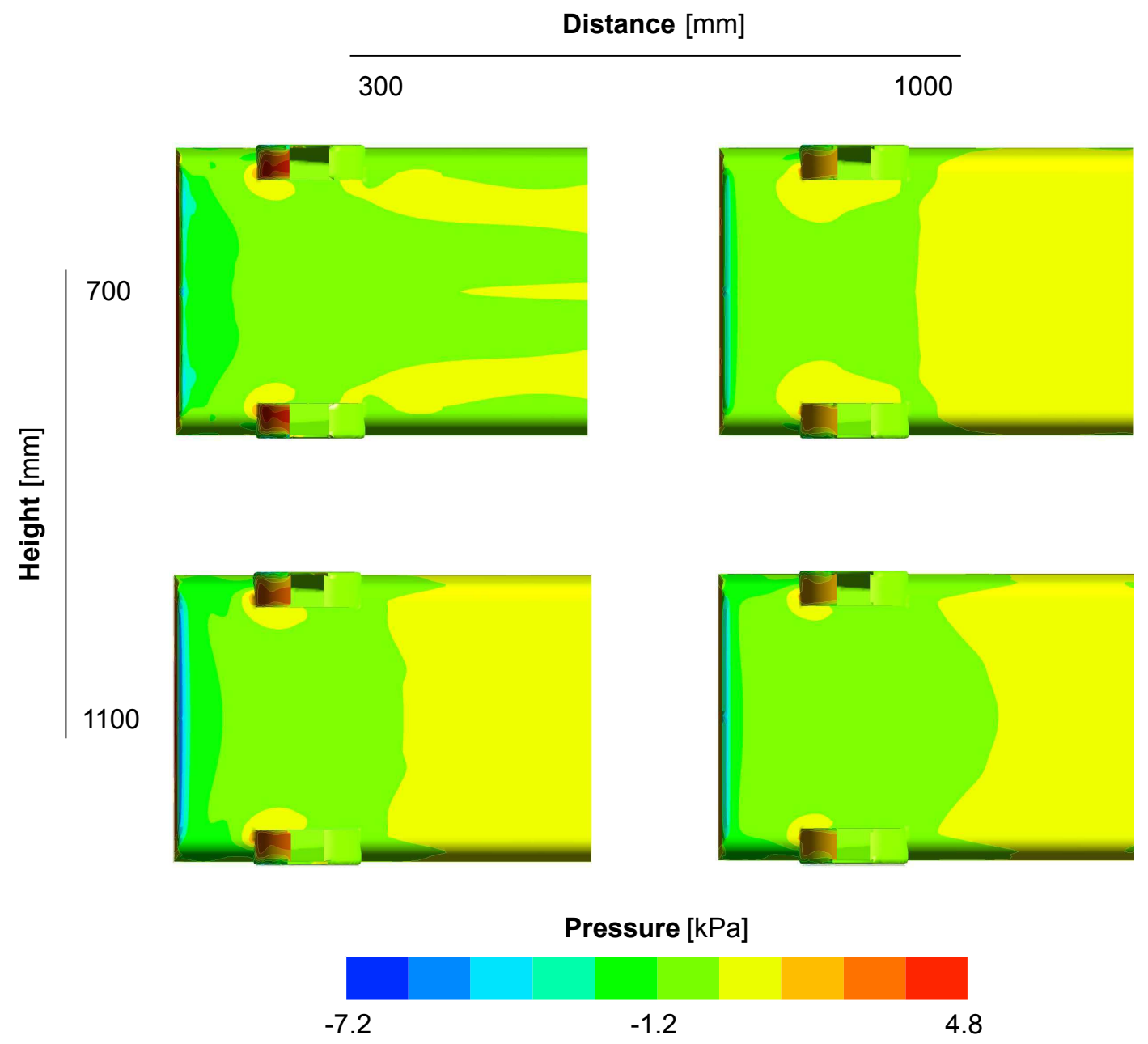

Figure 11: Wind blower test cell results: Bottom view of car surface pressure distribution. 


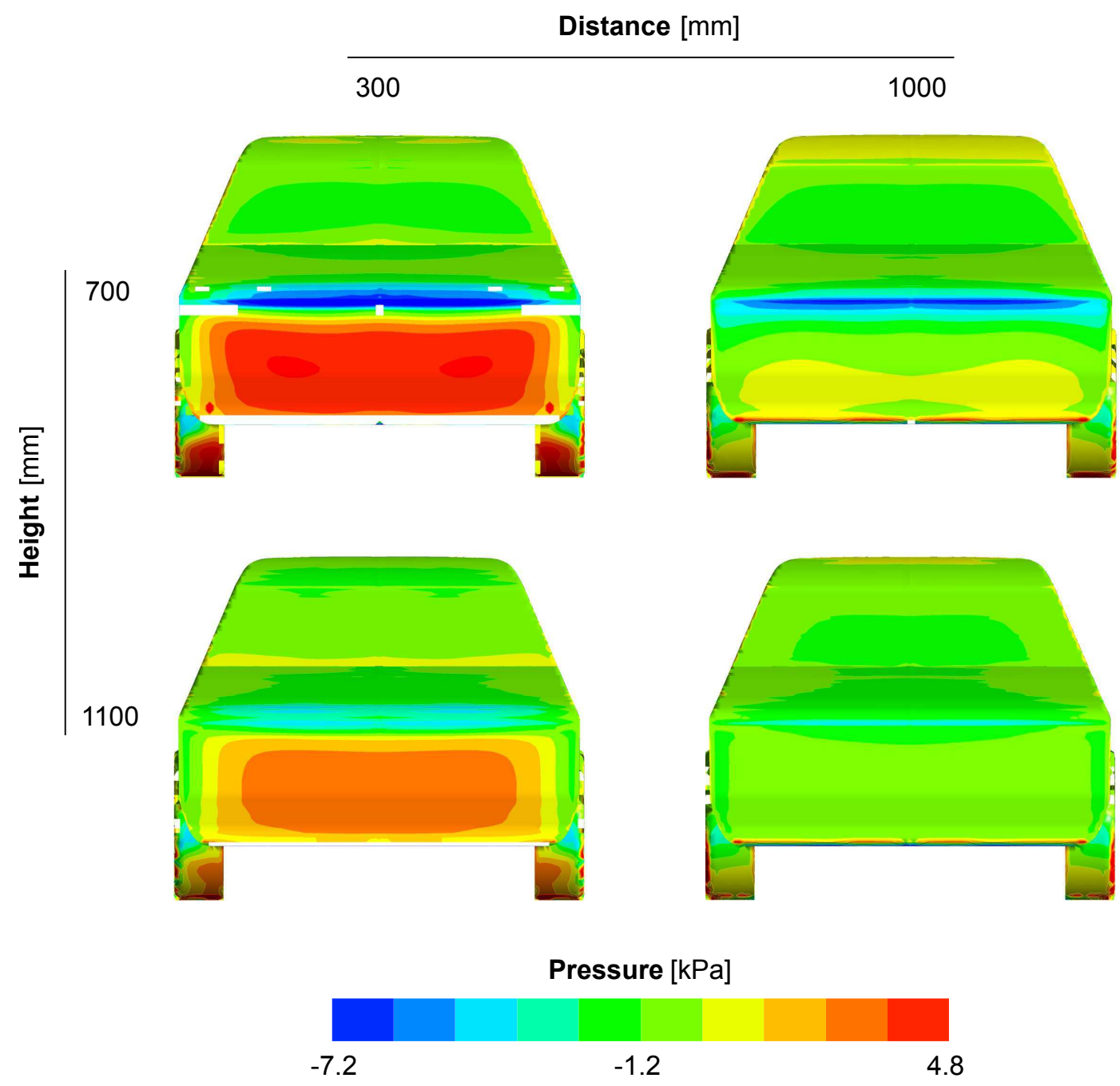

Figure 12: Pressure difference on car front bodywork between wind blower (test cell) and on-road result. 


\section{Distance $[\mathrm{mm}]$}

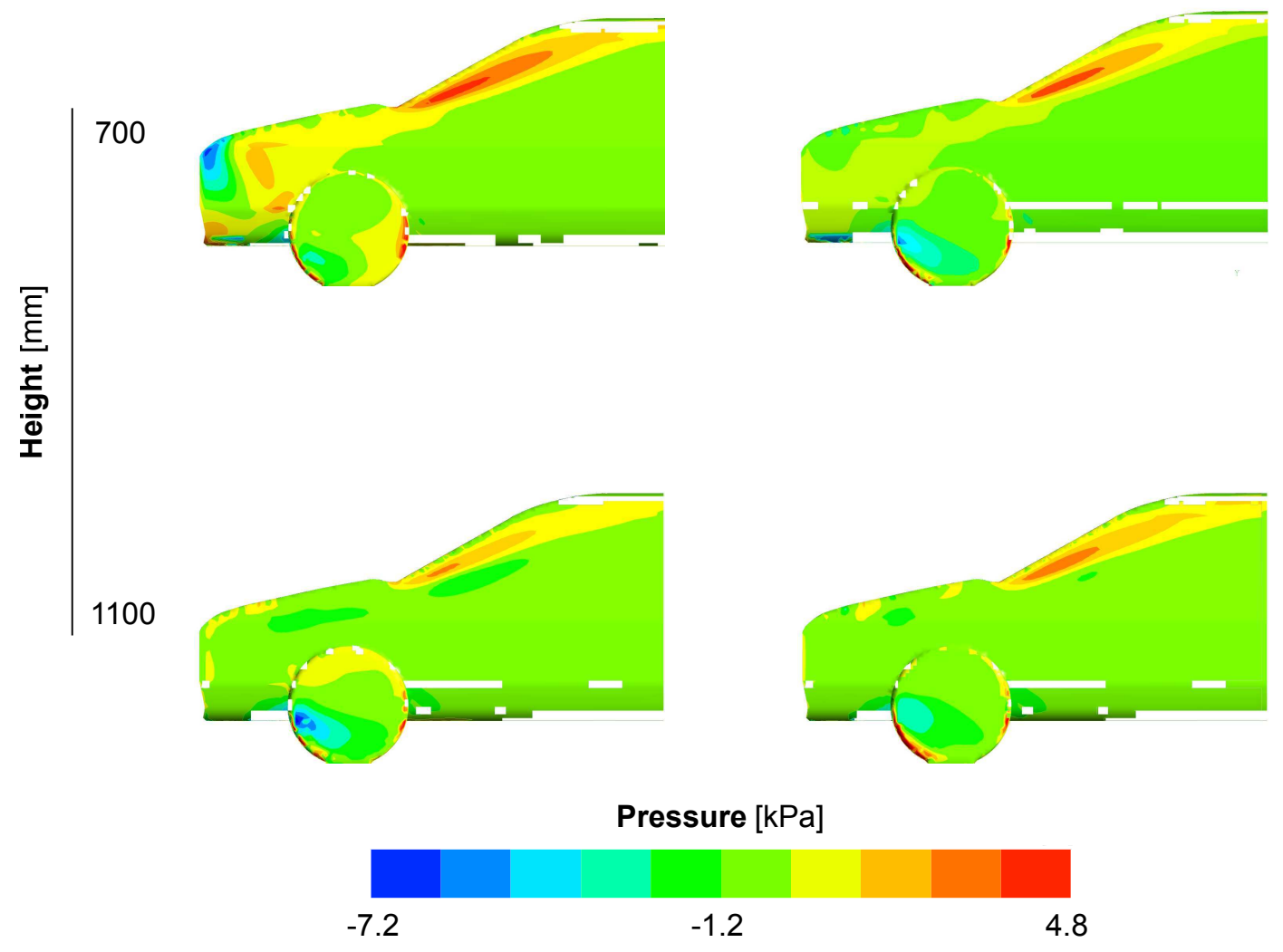

Figure 13: Pressure difference on car side bodywork between wind blower (test cell) and on-road result. 

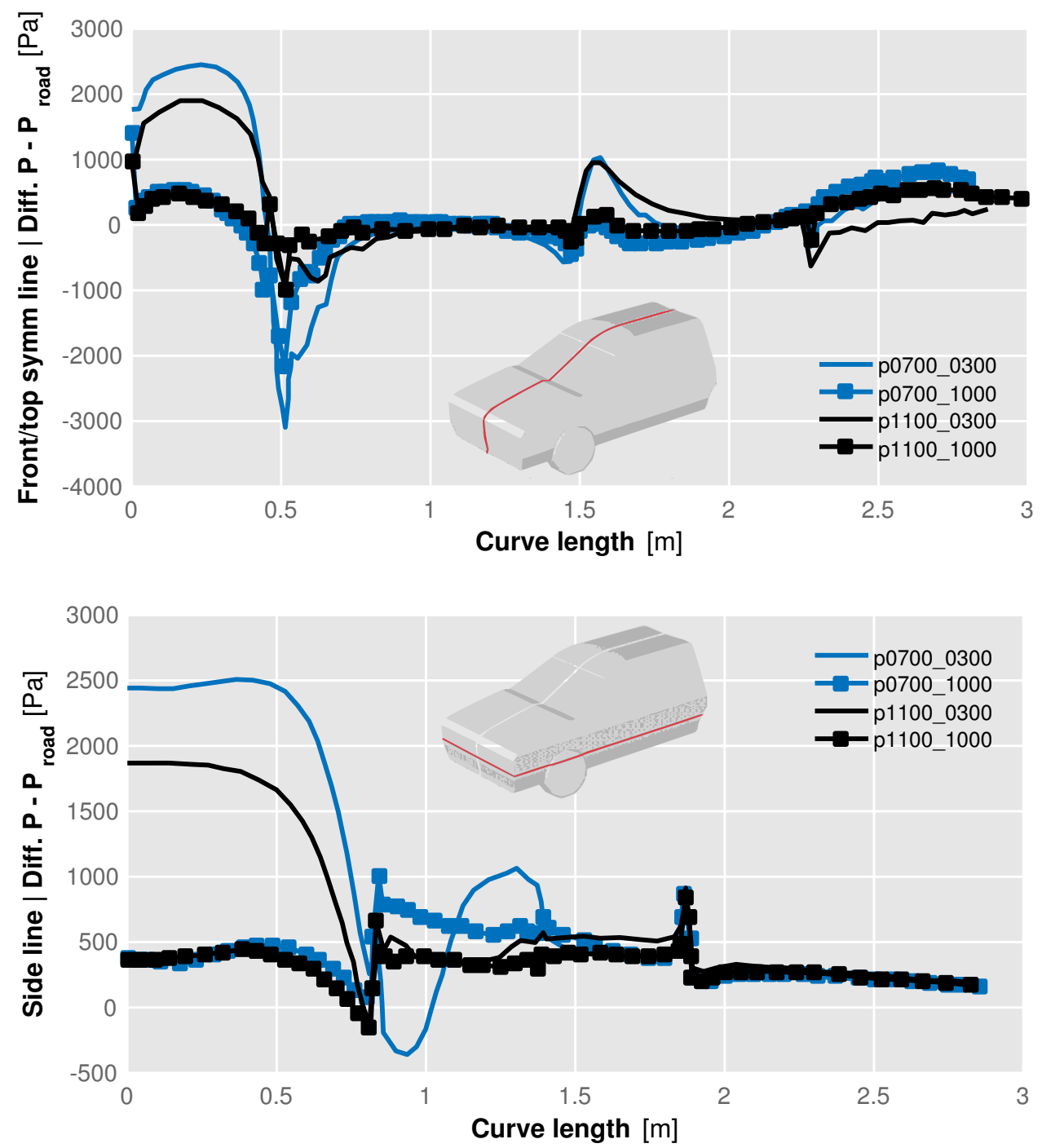

Figure 14: $\Delta p=p_{\text {blower }}-p_{\text {on-road }}$ calculated values for the studied wind blower configurations. Front/Top Symmetry Line (top) and Side Line at $0.50 \mathrm{~m}$ height(bottom). 


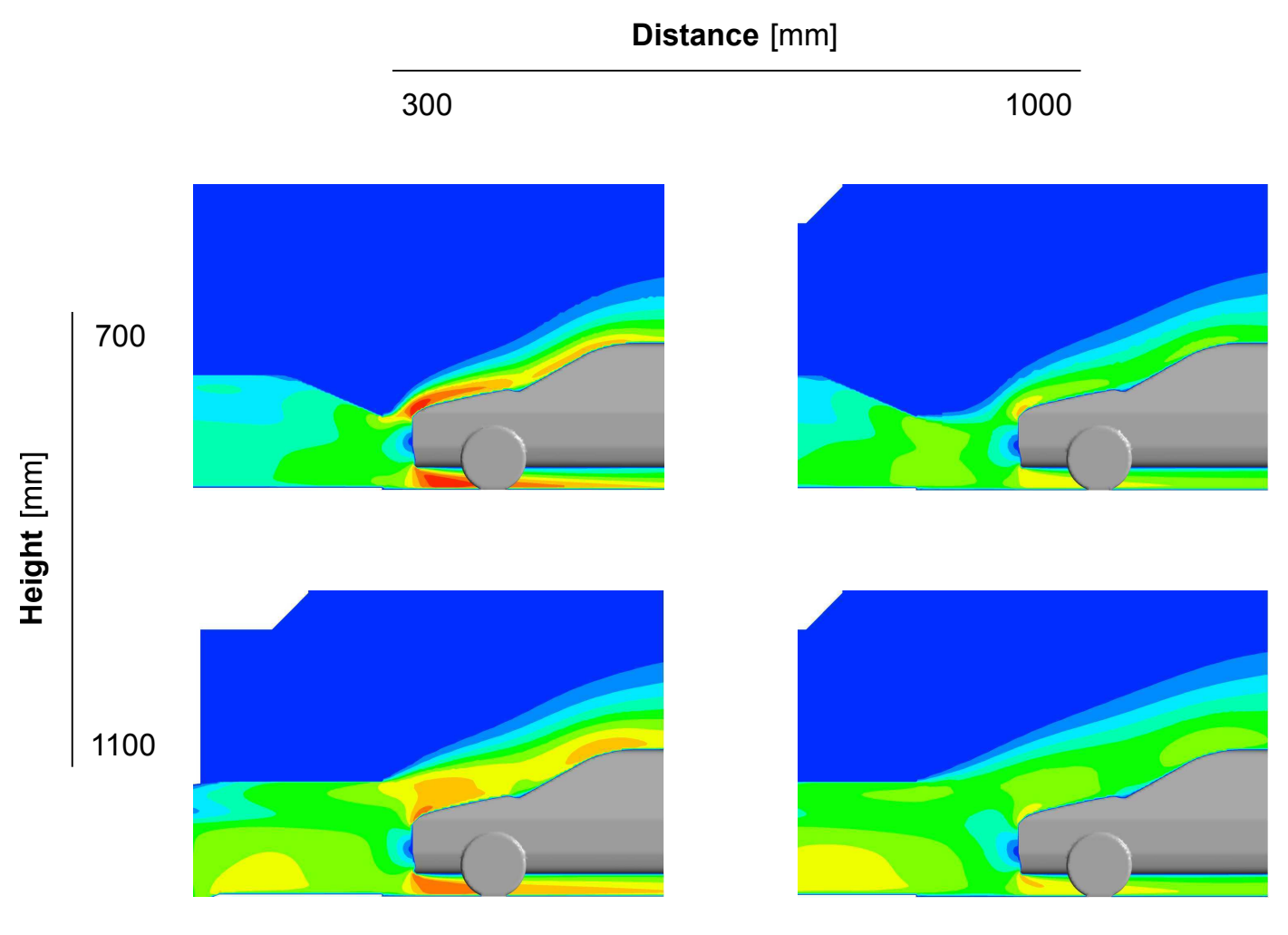

\section{On road}

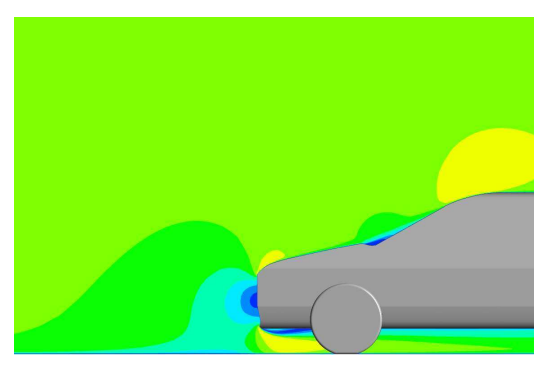

Velocity $[\mathrm{m} / \mathrm{s}]$

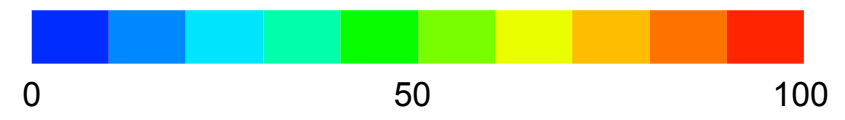

Figure 15: Velocity field contours on the vehicle in the symmetry plane. 


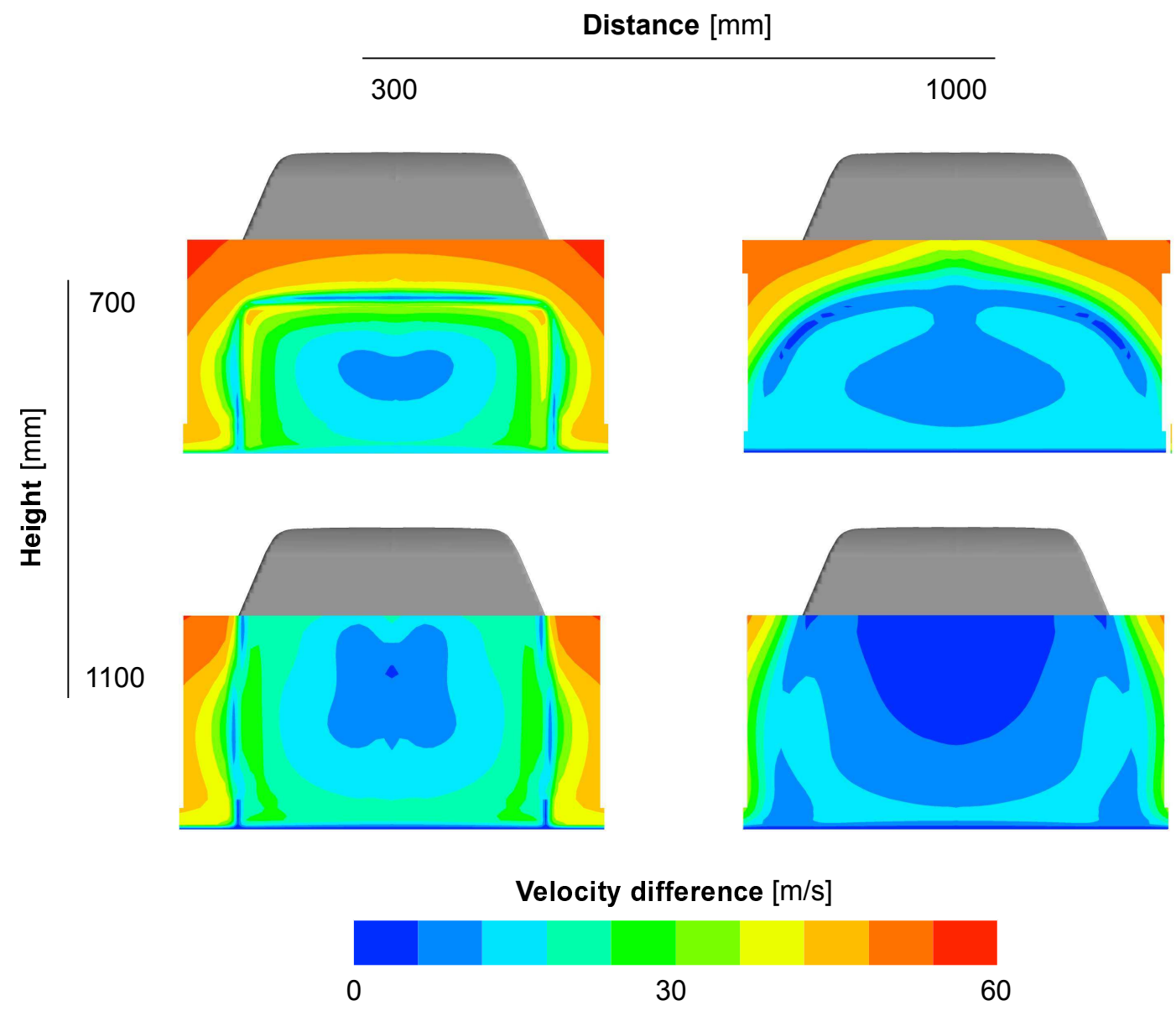

Figure 16: Velocity difference (wind blower-on-road) on plane located at $200 \mathrm{~mm}$ in front of the car. 